\title{
Preserved Motor Learning in Alzheimer's Disease: Implications for Anatomy and Behavior
}

\author{
Paul J. Eslinger and Antonio R. Damasio \\ Department of Neurology, Division of Behavioral Neurology, University of lowa College of Medicine, lowa City, \\ lowa 52242
}

\begin{abstract}
Learning and retention of 3 types of information were examined in patients with Alzheimer's disease (AD) and in normal controls. While patients were unable to learn series of frequent words and unfamiliar faces, they improved significantly in a motor skill, showing a learning curve similar to controls. Furthermore, no significant loss of the motor skill was evident in a 20 min delay trial. Such dissociation in learning has not been noted previously in AD, although it has been noted in amnesias caused by other disease processes. The results support the existence of two, relatively independent, learning systems related to "declarative" knowledge and "procedural" knowledge. Judging from the pathologic correlates of these amnesias, the declarative knowledge system appears to be associated with corticotemporo/limbic structures, while the procedural system is likely to depend on corticocerebellar/striatal structures. The data also offer additional cognitive correlates for the selective damage to neural systems recently identified in $\mathrm{AD}$.
\end{abstract}

A frequent early sign of Alzheimer's disease (AD) is an unremitting impairment of learning and memory, leading to a pervasive global amnesia and eventually a multimodal agnosia. While the memory disorder is accompanied by other cognitive changes, it remains quite prominent throughout the disease. Pervasive amnesia is also known to occur after focal damage to temporal lobe structures (Barbizet et al., 1978; Damasio et al., 1985a; Scoville and Milner, 1957), 10 medial diencephalic nuclei (Butters and Cermak, 1980; Graff-Radford et al., 1985; Squire and Moore, 1979; Teuber et al., 1968), or to basal forebrain nuclei (Damasio et al., 1985b). Despite profound memory disorder, however, these amnesics are able to learn and retain a variety of motor and perceptual skills (Cermak et al., 1973; Cohen and Squire, 1980; Corkin, 1968; Damasio et al., 1985a; Milner, 1966). Using standard paradigms of motor, verbal, and visual learning, we designed this study to ascertain whether a similar pattern of dissociation is evident in the amnesia caused by $\mathrm{AD}$.

\section{Materials and Methods}

Eight patients with the diagnosis of probable senile dementia of the Alzheimer type (SDAT) and 8 healthy controls were studied. The SDAT subjects met current clinical and laboratory diagnostic criteria (McKhann et al., 1984; Terry and Katzman, 1983), and were in moderate stages of dementia (i.e., having clearly detected major impairments of anterograde and retrograde memory, temporal oricntation, and other cognitive functions on neuropsychological assessment; some supervi-

\footnotetext{
Received Jan. 13, 1986; revised Apr. 14, 1986; accepted Apr. 17, 1986.

This work was supported by NINCDS Grant P01 NS 19632-02. We thank Dr. Arthur Benton and Dr. Daniel Tranel for their valuable criticism of the manuscript, and Scott Ramsey for help with data collection

Correspondence should be addressed to Paul Eslinger, Ph.D., Department of Neurology, University of Iowa Hospitals and Clinics, Iowa City, IA 52242.

Copyright (C) 1986 Society for Neuroscience $0270-6474 / 86 / 103006-04 \$ 02.00 / 0$
}

sion required in daily living at home; preserved social graces and ability to cooperate and follow instructions in structured testing sessions). None had motor or sensory impairment, hemispatial neglect, visual agnosia, visual disorientation syndrome, optic ataxia, or ocular apraxia. Duration of symptoms averaged 4 years (range $2 \frac{1}{2}-9$ years). The controls were volunteers with no history or evidence of neurologic or psychiatric disorder. The groups were similar in age (SDAT: $\bar{X}=71.4$ years, range 58-82 years; controls: $\bar{X}=70.8$ years, range $55-80$ years; $t(14)=0.16$, $p>0.87$ ), but educational background differed (SDAT: $\bar{X}=10$ years; controls: $\bar{X}=16$ years; $t(14)=5.06, p<0.01$ ).

There were 3 learning experiments. Each comprised 5 consecutive learning trials and 1 delayed trial to assess retention 20 min later. In experiment 1 , subjects held the stylus of a rotary pursuit apparatus in their preferred hand, rested it on the small metal target, and tried to maintain contact with the target as it rotated at $30 \mathrm{rpm}$. Each of the 5 learning trials lasted $20 \mathrm{sec}$; intertrial interval was $20 \mathrm{sec}$. A stopclock and impulse counter measured total time on target and the number of impulses (i.e., number of times the stylus lost and then regained contact with the target).

In experiment 2, subjects listened to a 10-item grocery list and, in a free-recall format, responded with as many items as they could, in any order, immediately following presentation. Though no time limit for responding was enforced, subjects generally completed responses within $60 \mathrm{sec}$. Instructions were repeated on each succeeding trial, urging subjects to recall all the items, even those already recalled on previous trials. Each trial was scored for number of correct items recalled. The delayed-recall trial was followed by a recognition test comprised of the target words and distractor items. A signal detection analysis, with calculation of $d^{\prime}$, was used to examine verbal recognition performance.

In experiment 3 , subjects examined pictures of 8 unfamiliar faces for $20 \mathrm{sec}$. From a multiple-choice display of 20 faces, subjects then chose the 8 original faces, even if they were not certain of all choices. Though no time limit for responding was enforced, subjects generally completed responses within $60-90 \mathrm{sec}$. Performance was scored for number correct.

All experimental procedures were fully completed, with the exception of facial learning in 1 SDAT subject whose testing was interrupted. Analysis of facial learning, therefore, was based on the results of the 7 remaining pairs of subjects. For each of the learning experiments, a $2 \times$ 5 (Groups $\times$ Learning Trials) analysis of variance was used to examine results. Retention on the delayed trial was examined in relation to the last learning trial (trial 5) in a $2 \times 2$ (Groups $\times$ Trials) analysis of variance. Our principal interest in the latter analysis was in determining if a significant interaction effect would occur.

\section{Results}

SDAT patients and controls had a similar pattern of motor lcarning in cxperiment 1 (Fig. $1 A$ ). Analysis of time-on-target data revealed a significant trials effect $(F(4,56)=21.71, p<$ $0.001)$ and no interaction $(p>0.35)$. The SDAT group initially performed at a much lower level (55\% of controls), but this difference gradually diminished to $93 \%$ (trial 4 ) and $87 \%$ (trial 5) of control levels. Thcir improvement represented a change of $161 \%$ over learning trials (Fig. 2), with every SDAT subject showing improvement. Although the groups did not differ statistically in level of performance $(F(1,14)=2.86, p=0.11)$, a trend toward a difference was possibly evident. Given this result 

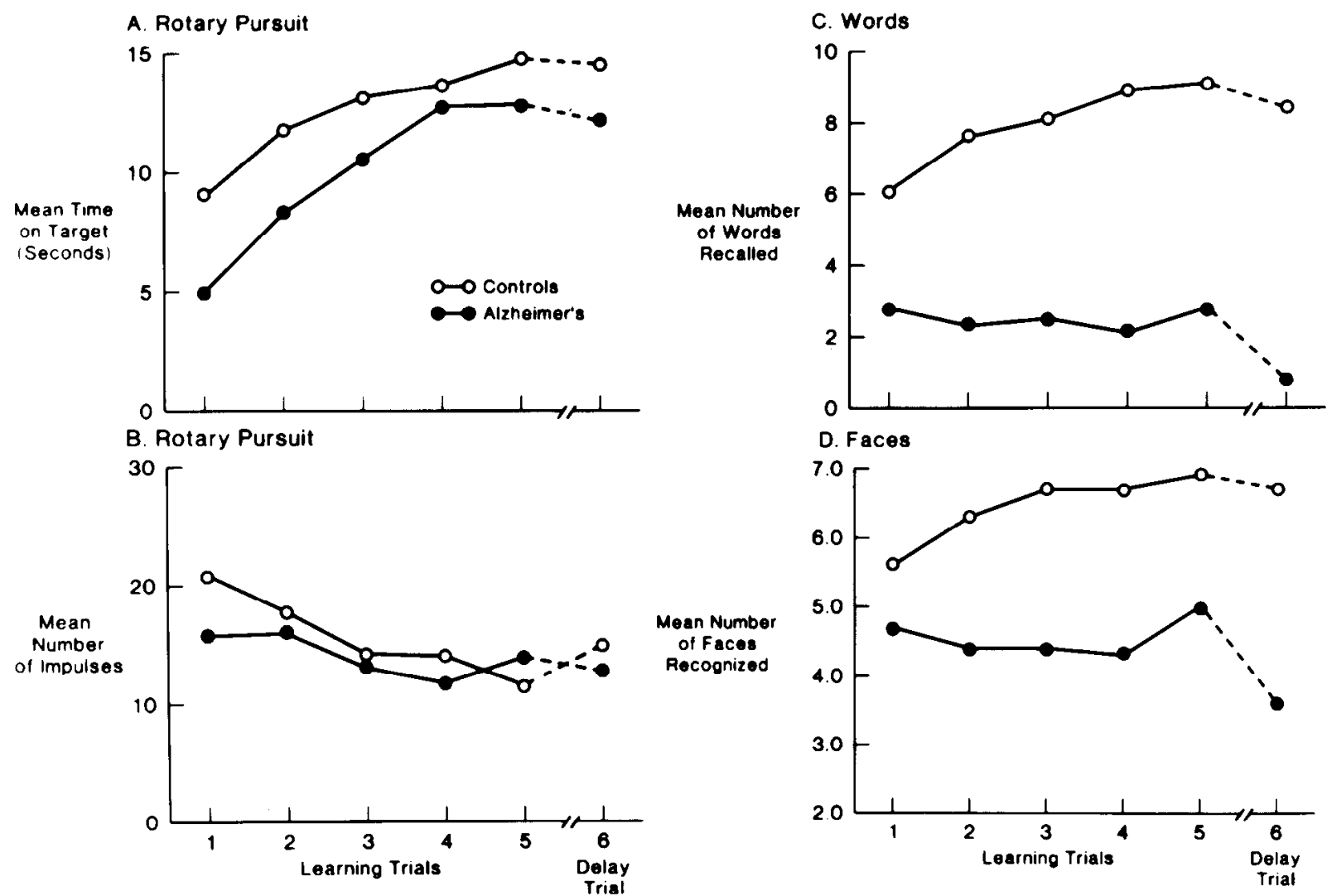

Figure 1. Learning and retention of a rotary pursuit motor skill, as measured by time on target $(A)$ and number of impulses $(B)$, recall of a 10 item grocery list $(C)$, and recognition of 8 unfamiliar faces $(D)$. After 5 learning trials, retention was measured after a 20 min delay.

and the small sample sizes, we felt that the question of performance level should be subject to future study. Analysis of performance on the last learning trial and on the delayed trial revealed no interaction $(p>0.58)$, group $(p>0.17)$, or trials $(p>0.42)$ effects, suggesting a comparable retention of what was learned (Fig. 3).

Analysis of rotary-pursuit impulses (Fig. $1 B$ ) showed results similar to time-on-target, with which it was highly correlated (SDAT: $r=0.79, t(6)=3.14, p<0.05$; controls: $r=0.99$, $t(6)=17.14, p<0.001)$. A significant trials effect was found $(F(4,56)=5.60, p<0.001)$, but no group difference $(p>0.56)$ or interaction $(p>0.18)$. Analysis of performances on the last learning trial and on the delayed trial revealed an interaction effect $(F(1,14)=7.16, p<0.02)$, with the control group showing more impulses and the SDAT group fewer impulses than on their last learning trial (Fig. 3). No group $(p>0.98)$ or trials $(p>0.23)$ effects were supported.

In experiment 2 , which required learning of verbal information, significant group $(F(1,14)=103.61, p<0.001)$, trials $(F(4,56)=4.46, p<0.01)$, and group $\times$ trials $(F(4,56)=5.92$, $p<0.001)$ interaction effects were evident. The learning curve of the control group consistently improved, while that of the SDAT group was flat (Figs. $1 C$ and 2 ). The initial verbal performance level of the SDAT group was $45 \%$ of controls, but by trial 5 it represented only $30 \%$ of control levels. In analysis of the last learning trial and the delayed-trial data, a significant interaction effect was found $(F(1,14)=5.65, p<0.05)$, as well as group $(F(1,14)=161.41, p<0.001)$ and trials $(F(1,14)=$ $27.32, p<0.001)$ effects. The SDAT group fell to, almost zero in verbal recall ( $73 \%$ decline vs $11 \%$ for controls) (Fig. 3$)$. The verbal recognition task, following the delayed-recall trial, also showed a performance level significantly lower than controls
(SDAT: $\bar{X} d^{\prime}=1.14$; controls: $\bar{X} d^{\prime}=4.64 ; t(14)=10.0, p<$ $0.001)$.

In experiment 3 , the learning of unfamiliar faces was difficult for SDAT patients and controls (Figs. $1 D$ and 2). While the groups differed significantly in performance level $(F(1,12)=$ $15.50, p<0.01)$, no trials effect $(p>0.22)$ or group $\times$ trials interaction $(p>0.17)$ was found. Controls appeared to improve through the first 3 trials, but little thereafter. The SDAT group began at $85 \%$ of control levels, but by trial 3 had fallen to $66 \%$. Analysis of learning and retention data revealed a significant interaction $(F(1,12)=6.57, p<0.05)$, as well as group $(F(1,12)=$ $18.28, p<0.01)$ and trials $(F(1,12)=9.81, p<0.01)$ effects. Retention of the SDAT group dropped to almost a chance recognition level (29\% decline vs $2 \%$ for controls) (Fig. 3).

\section{Discussion}

SDAT subjects showed a striking dissociation in their ability to learn and retain different types of information. As expected, they were profoundly amnesic, showing poor acquisition of common words and unfamiliar faces, no learning curve over trials, and even poorer retention after a short delay. As with other amnesics, the findings suggest a loss of neural mechanisms necessary for learning such verbal and nonverbal information. However, the SDAT subjects learned a motor skill in a manner similar to controls, indicating preservation of the neural structures that integrate the visual, motor, and kinesthetic information used in the task, and that permit the development and storage of a motor program. This dissociation has not been observed previously in subjects with dementia of the Alzheimer type, although it is in keeping with a previous report that some subjects with mild SDAT could learn a perceptual skill (Corkin, 1982). 


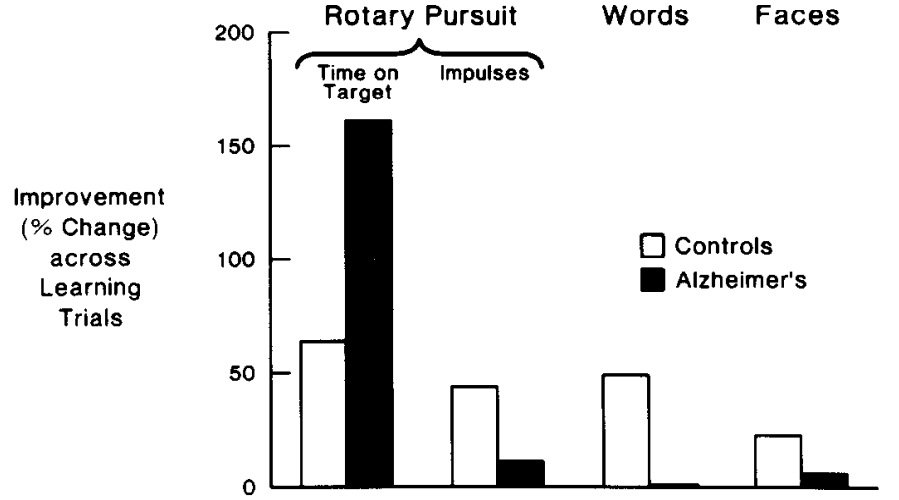

Figure 2. Learning of the rotary pursuit motor skill, 10-item grocery list, and 8 unfamiliar faces over trials, as measured by percentage of change from trial 1 .

A variety of contrasting terms has been used to conceptualize this dissociation in learning; all are aimed at characterizing the fundamental distinction between the domains of preserved and disturbed memory function in the amnesias. Most notably, human cognitive research (Cohen and Squire, 1980; Moscovitch, 1982; Squire and Cohen, 1984) and experimental animal research (Mishkin and Petri, 1984; Mishkin et al., 1984) have emphasized that the nature of information, the characteristics of the tasks, and the mode of response are different in these learning paradigms. The differences are so marked that it is not even reasonable to compare the paradigms in terms of difficulty; one merely states that they must require different cognitive and neural mechanisms. Cohen and Squire (1980) have applied the terms "procedural" and "declarative" knowledge to these different types of memory. Procedural knowledge refers to motor, perceptual, and even cognitive skills that are acquired incrementally and principally by practicing the skill itself. Procedural knowledge appears to be a more comprehensive term than the designation "habits" (Mishkin and Petri, 1984; Mishkin et al., 1984), which emphasizes the strengthening of principally stimulus-response associations. Declarative knowledge, in contrast, depends on the memory traces of sensory experiences of given stimuli. It ranges in complexity from the memory of a prototype object (e.g., a pen) to complex, autobiographic contextual memories (e.g., remembering which personal pen was used to write a specific report). The common words and new faces that the SDAT subjects failed to learn in experiments 2 and 3 are examples of declarative knowledge.

The marked disparity between procedural and declarative learning in SDAT appears similar to that of the amnesias caused by focal lesions in humans and nonhuman primates, and is strong evidence that SDAT does not randomly or diffusely damage the anatomical substrates of learning and memory. On the contrary, the cellular damage of Alzheimer's disease must be selective and involve especially the hippocampal system (Ball, 1978; Hyman et al., 1984; Kemper, 1978; McLardy, 1970; Van Hoesen et al., 1985). This system has been repeatedly implicated in the learning and retention of declarative knowledge, but not in the learning of procedural knowledge (Corkin, 1968; Damasio et al., 1985a; Milner, 1966). Recent reports provide new evidence that Alzheimer's disease involves highly selective cellular and laminar change in layers II and IV of entorhinal cortex and in all layers of the subiculum, respectively the crucial staging arcas for hippocampal input and output from and to the cerebral cortex (Hyman et al., 1984; Van Hoesen et al., 1985). These pathologic changes are probably related to the verbal and facial memory impairments in our SDAT subjects.

Motor learning is likely to require different neural structures,

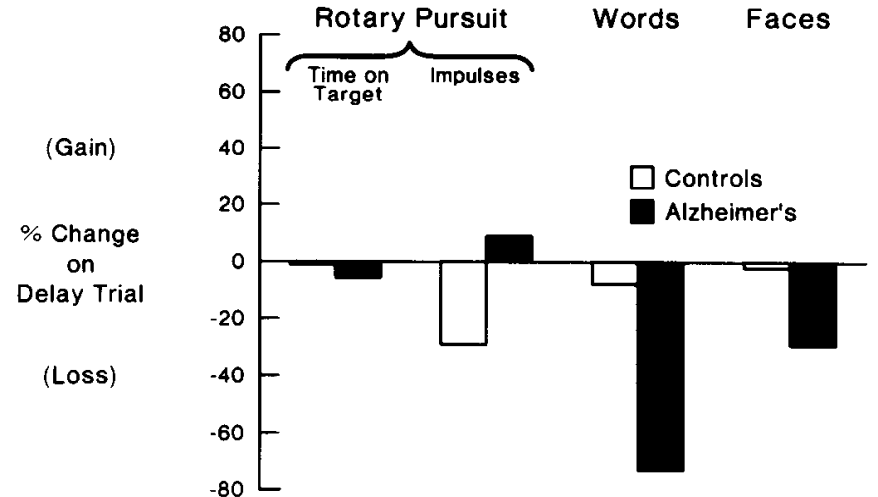

Figure 3. Retention of motor learning, verbal learning and face learning after a 20 min delay interval. In contrast to the words and faces, retention of the motor skill (time on target) did not differ between controls and patients with Alzheimer's disease.

which can operate independently from the hippocampal system. These would include components of the motor system in the cerebellum, basal ganglia, thalamus, motor and premotor cortices, and related pathways, as well as somatosensory and visual cortices. It is of interest to note, in this regard, that specific damage in cerebellar structures has been shown to abolish conditioned motor responses (McCormick and Thompson, 1984). It is also noteworthy that most motor system structures appear resistant to the degenerative changes of Alzheimer's disease (Terry and Katzman, 1983). All of these findings support the notion that Alzheimer's disease causes damage in selected neural systems that are especially vulnerable to its pathologic mechanisms.

It remains to be determined whether this dissociation is characteristic of all or most SDAT patients. On the basis of our current sample, we suspect that the dissociation is likely to occur in many mildly and moderately advanced cases. Furthermore, the dissociation in learning may also be evident in other procedural learning paradigms. Finally, the findings may have potential therapeutic implications, as they suggest that occupational programs focused on motor activities might be reasonably successful in these patients. By providing some rewarding responses, they might be especially beneficial to patients, families, and caregivers engaged in the management of this untreatable illness.

\section{References}

Ball, M. J. (1978) Topographic distribution of neurofibrillary tangles and granulo-vascular degeneration in hippocampal cortex of aging and demented patients. Acta Neuropathol. (Berlin) 74: 173-178.

Barbizet, J., P. H. Duizabo, and J. Poirier (1978) Etude anatomoclinique d'un cas d'encephalite amnesiante d'origine herpetique. Rev. Neurol. 134: 241-253.

Butters, N., and L. S. Cermak (1980) Alcoholic Korsakoff's Syndrome, Academic, New York.

Cermak, L. S., R. Lcwis, N. Buttcrs, and H. Goodglass (1973) Role of verbal mediation in performance of motor tasks by Korsakoff patients. Percept. Mot. Skills 37: 259-262.

Cohen, N. J., and L. R. Squire (1980) Preserved learning and retention of pattern-analyzing skill in amnesia: Dissociation of knowing how and knowing that. Science 210: 207-210.

Corkin, S. (1968) Acquisition of motor skill after bilateral medial temporal-lobe excision. Neuropsychologia 6: 255-265.

Corkin, S. (1982) Some relationships between global amnesias and the memory impairments in Alzheimer's disease. In Alzheimer's Disease: $A$ Report of Progress in Research, S. Corkin, S. Davis, et al., eds., pp. 149-164, Raven, New York.

Damasio, A. R., P. J. Eslinger, H. Damasio, G. W. Van Hoesen, and S. Cornell (1985a) Multimodal amnesia syndrome following bilat- 
eral temporal and basal forebrain damage. Arch. Neurol. 42: 252259.

Damasio, A. R., N. R. Graff-Radford, P. J. Eslinger, H. Damasio, and N. Kassell (1985b) Amnesia following basal forebrain lesions. Arch. Neurol. 42: 263-271.

Graff-Radford, N. R., H. Damasio, T. Yamada, P. J. Eslinger, and A. R. Damasio (1985) Nonhaemorrhagic thalamic infarction. Brain 108: 485-516.

Hyman, B. T., G. W. Van Hoesen, A. R. Damasio, and C. Barnes (1984) Alzheimer's disease: Cell-specific pathology isolates the hippocampal formation. Science 225: 1168-1170.

Kemper, T. L. (1978) Senile dementia: A focal disease in the temporal lobe. In Senile Dementia: A Biomedical Approach, K. Nandy, ed., pp. 105-113, Elsevier-North Holland, Amsterdam.

McCormick, D. A., and R. F. Thompson (1984) Neuronal responses of the rabbit cerebellum during acquisition and performance of a classically-conditioned nictitating-eyelid response. J. Neurosci. 4: 2811-2822.

McKhann, G., D. Drachman, M. Folstein, R. Katzman, D. Price, and E. M. Stadlan (1984) Clinical diagnosis of Alzheimer's disease: Report of the NINCDS-ADRDA Work Group under the auspices of Department of Health and Human Services Task Force on Alzheimer's Disease. Neurology 34: 939-944.

McLardy, T. (1970) Memory function in hippocampal gyri but not in hippocampi. Int. J. Neurosci. 1: 113-118.

Milner, B. (1966) Amnesia following operation on the temporal lobes. In Amnesia, C. W. M. Whitty and O. L. Zangwill, eds., pp. 109-133, Butterworth, London.
Mishkin, M., and H. L. Petri (1984) Memories and habits: Some implications for the analyses of learning and retention. In Neuropsychology of Memory, L. R. Squire and N. Butters, eds., pp. 287296, Guilford, New York.

Mishkin, M., B. Malamut, and J. Bachevalier (1984) Memories and habits: Two neural systems. In Neurobiology of Learning and Memory, G. Lynch, J. L. McGaugh, and N. M. Weinberger, eds., pp. 6577, Guilford, New York.

Moscovitch, M. (1982) Multiple dissociations of function in amnesia. In Human Memory and Amnesia, L. S. Cermak, ed., pp. 337-370, Lawrence Erlbaum, Hillsdale, NJ.

Scoville, N. B., and B. Milner (1957) Loss of recent memory after bilateral hippocampal lesions. J. Neurol. Neurosurg. Psychiatry 209: 11-19.

Squire, L. R., and N. Cohen (1984) Human memory and amnesia. In Neurobiology of Learning and Memory, G. Lynch, J. L. McGaugh, and N. M. Weinberger, eds., pp. 3-63, Guilford, New York.

Squire, L. R., and R. Y. Moore (1979) Dorsal thalamic lesion in a noted case of chronic memory dysfunction. Ann. Neurol. 6: 503-506.

Terry, R. D., and R. Katzman (1983) Senile dementia of the Alzheimer type. Ann. Neurol. 14: 497-506.

Teuber, H.-L., B. Milner, and H. G. Vaughan (1968) Persistent anterograde amnesia after stab wound of the basal brain. Neuropsychologia 6: 267-282.

Van Hoesen, G. W., A. R. Damasio, and B. T. Hyman (1985) Perforant pathway destruction and other temporal lobe pathology in $\mathrm{Alz}$ heimer's disease. Neurology 34: 219. 